\title{
A Study on the Desulfurization Efficiency of Limestone Sludge with Various Admixtures
}

\author{
Sung Kwan Seo*, Yong Sik Chu**, Kwang Bo Shim*, Jong Kyu Lee*, and Hun Song** \\ *Energy \& Environmental Division, Korea Institute of Ceramic Engineering and Technology, Jinju 52851, Korea \\ **Division of Materials Science and Engineering, Hanyang University, Seoul 04763, Korea \\ (Received July 1, 2015; Revised October 14, 2015; Accepted October 15, 2015)
}

\begin{abstract}
The flue gas desulfurization (FGD) process is one of the most effective methods to reduce the amount of $\mathrm{SO}_{2}$ gas (up to $90 \%$ ) generated by the use of fossil fuel. Limestone is usually used as a desulfurizing agent in the wet-type FGD process; however, the limestone reserves of domestic mines have become exhausted. In this study, limestone sludge produced from the steel works process is used as a desulfurizing agent. Seven different types of additives are also used to improve the efficiency of the desulfurization process. As a result, alkaline additive is identified as the least effective additive, while certain types of organic acids show higher efficiency. It is also observed that the amount of FGD gypsum, which is a by-product of the FGD process, increases with the used of some of those additives.
\end{abstract}

Key words : FGD systems, Limestone sludge, Organic acid, Alkali admixture agent, Gypsum

\section{Introduction}

$I_{\mathrm{i} i}^{\mathrm{n}}$ $\mathrm{n}$ the early 20th century, the usage of fossil fuels was increased explosively as the industry was developed drastically. Also, with an increase in the usage of fossil fuels, environment contamination problems emerged, and environment regulations for discharge of contaminants were started in the middle of the 20th century in the advanced countries such as US, Germany, Japan as a center. To respond to such environment regulations, studies on processing technology for contaminants were actively conducted, with the interests being concentrated on the processing technologies for NOx, SOx, etc. in particular.

Flue Gas desulfurization(FGD) is a removal method for $\mathrm{SO}_{2}$ gas where the removal ratio of sulfur oxides produced by use of fossil fuels reaches a level of $90 \%{ }^{1)}$ Flue Gas desulfuriziation refers to a technique for removing SOx contained in the exhaust gas after combustion by using the principles of Absorption, Adsorption, Oxidation and Reduction, etc. The existing FSD techniques may be divided into the dry method and the wet method, depending on the water contents of the desulfurizing agent. As a representative desulfurizing agent used for wet FSD technique, magnesium hydroxide $\left(\mathrm{Mg}(\mathrm{OH})_{2}\right)$ and limestone may be named, and the limestone of lower prices compared with those of the magnesium hydroxide $\left(\mathrm{Mg}(\mathrm{OH})_{2}\right)$ is mainly used domestically. However, since the use of low-quality limestone is almost

${ }^{\dagger}$ Corresponding author : Yong Sik Chu

E-mail : yschu@kicet.re.kr

Tel : +82-2-3282-2423 Fax : +82-2-3282-2430 impossible for the reasons of operation efficiency and economy, etc., only high-quality limestone is used as the desulfurizing agent. However, as the domestic high-quality limestone is employed as the main and subsidiary raw materials by cement manufacturers, ironworks, etc., a limit of the reserves is being revealed. Consequently, development of desulfurizing agents to substitute for the high-quality limestone is being actively performed, and the study to use limestone sludge produced at ironworks as a desulfurizing agent may be considered as an example. $\left.{ }^{2}\right)$ The limestone sludge refers to a designated waste of about $15 \%$ in moisture content level which is produced upon manufacturing of quicklime used as a subsidiary material in the iron making process, and the desulfurizing effects may be obtained on an equivalent level to that for the existing limestone slurry when removal tests for $\mathrm{SO}_{2}$ are conducted after mixing of the limestone slurry used in the existing desulfurizing process with the limestone sludge by a given ratio. ${ }^{2}$

Meanwhile, efficiencies and operation costs of FGD process to remove $\mathrm{SO}_{2}$ are affected by several factors. Particularly, the removal efficiency of $\mathrm{SO}_{2}$ gas is determined by $\mathrm{pH}$, temperature, solid content, etc. of the slurry used as a desulfurizing agent for the wet FGD process. Particularly, degradation phenomena for solubility and dissolution rate of $\mathrm{SO}_{2}$ gas are suppressed when $\mathrm{pH}$ of the slurry is low, while degradation in solubility and dissolution rate occurs when the $\mathrm{pH}$ is high. To solve this problem, either the amount of limestone is controlled or the buffering admixtures for $\mathrm{pH}$ control or the alkali admixtures to improve material transfer rates of $\mathrm{SO}_{2}$ etc. are employed. ${ }^{3,4)}$

Therefore, in the present study, the measures allowing improvement of desulfurizing efficiencies of the limestone 
sludge were reviewed by comparative evaluation of desulfurizing performance of each admixture after application of organic acids and alkali admixtures to the limestone sludge.

\section{Experimental Procedure}

For comparative evaluation of performance of the desulfurizing agent as a function of admixture types, experiments for comparison of desulfurizing efficiencies were conducted. As the desulfurizing agents used for the experiments, samples of the limestone slurry currently used for desulfurizing process at the thermal power plant B mixed with the limestone sludge from the ironwork $\mathrm{H}$ by the ratio of $6: 4$ were used with the moisture content being controlled to be $70 \%$. Also, the admixtures used for performance evaluation included DBA, OR(acidic solution prepared by fermentation of food wastes) and $\mathrm{H}_{2} \mathrm{SO}_{4}, \mathrm{MgO}, \mathrm{MgSO}_{4}$, Acetic acid, Formic acid, etc. The added amounts of the above admixtures compared with the total amount of desulfurizing agents were controlled to be $1 \%, 3 \%, 5 \%$, and the $\mathrm{pH}$ characteristics, the desulfurizing efficiencies and the produced amount of gypsum, etc. were comparatively evaluated.

As a method for comparative evaluation of desulfurizing efficiencies, gas removal experiment was conducted by using a sealed desiccator, with $500 \mathrm{ppm}$ of $\mathrm{SO}_{2}$ being prepared(N2 balance) and used as a Flue gas. In the experimental procedure, $17 \mathrm{~g}$ of desulfurizing agent was placed in the sealed desiccator, followed by injection of $500 \mathrm{ppm}$ of $\mathrm{SO}_{2}$ gas for 2 minutes, and the concentrations of $\mathrm{SO}_{2}$ were measured at each time ( $0 \mathrm{~min}, 10 \mathrm{~min}, 30 \mathrm{~min}, 60 \mathrm{~min}, 90$ $\mathrm{min})$ by using a direct reading-type gas detector tube (GV110S, GASTEC Co., JAPAN) after which the desulfurizing efficiencies were measured (Fig. 1). For the desulfurizing agent with the measurement for concentration of $\mathrm{SO}_{2}$ gas completed, X-ray diffraction(XRD) patterns were measured by using a X-ray diffraction analyzer (D5005D, Siemens Co., GERMANY) after drying for $12 \mathrm{~h}$ in a dryer at $40^{\circ} \mathrm{C}(\mathrm{J}$ 300M, JISICO Co., KOREA), and G/C ratios (Gypsum main
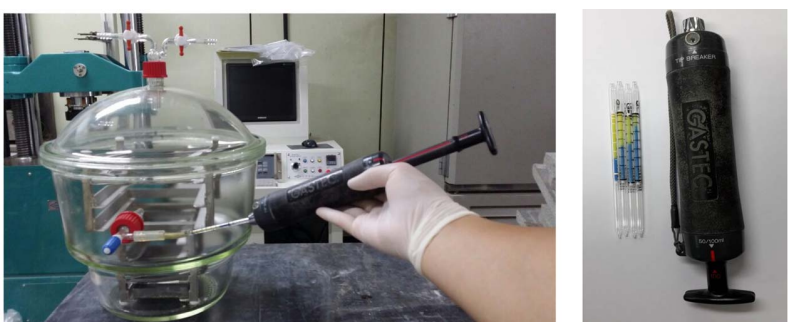

Fig. 1. Desulfurization experiment. peak intensity / Calcite main peak intensity) were calculated for comparative analysis of reaction efficiencies of the desulfurizing agents.

For the samples with the analysis of XRD pattern completed, observation and EDS qualitative analysis of the microstructures of limestone sludge were conducted by using a scanning electron microscope (SM300, TOPCON Co., JAPAN) to perform analyses of shape and purity, etc. for the produced gypsum.

\section{Results and Discussion}

Types of the admixture may be classified into water-soluble alkali admixtures and organic acid admixtures, and the water-soluble alkali admixtures are in the form of sulfite, sulfate, carbonate, hydroxide salts which improve the material transfer rates of $\mathrm{SO}_{2}$ by being dissolved in water and providing basicity. ${ }^{5)}$ Also, the organic acid has a buffering action in the reactor, with the admixtures for such action should acting as an alkali in the solution where the reaction occurs. Such admixtures should have the buffering capability at gas-liquid interfaces $(\mathrm{pH} 3 \sim 3.5)$ and in the whole reaction solution $(\mathrm{pH} 5 \sim 5.5){ }^{6)}$

The $\mathrm{pH}$ characteristics as a function of admixture mixing are shown in Table 1.

When $\mathrm{pH}$ changes of the slurry are considered as a function of admixture mixing, the $\mathrm{pH}$ is lowered as the contents of acidic admixture are increased, while the $\mathrm{pH}$ changes as a function of the alkali admixture content were nor shown to be large. Particularly, the $\mathrm{pH}$ changes resulting from mixing of DBA and sulfuric acid were shown to be large, which is considered to be caused by the fact that both DBA and sulfuric acid have a strong acidity. After $17 \mathrm{~g}$ of the sample with completion of $\mathrm{pH}$ measurement was taken, the experiments for measuring the change in $\mathrm{SO}_{2}$ concentrations were conducted by using a desiccator, with the results shown in Fig. 2.

When the changes in $\mathrm{SO}_{2}$ gas concentration are considered as a function of types and contents of the admixture, drastic reaction could be seen to have occurred during the initial 30 minutes. Also, in the reaction section during the initial 30 minutes, the removal rates of $\mathrm{DBA}$ and $\mathrm{SO}_{2}$ gas of sulfuric acid were shown to be slower as compared with other admixtures, which is attributed to the $\mathrm{pH}$ effect of the desulfurizing agent. In general, the removal rates of $\mathrm{SO}_{2}$ gas are known to be the higher, the higher the injected L/G ratios and the $\mathrm{pH}$ 's, and the $\mathrm{pH}$ control technique can be seen to be an important factor upon removal reaction of $\mathrm{SO}_{2}$ gas.

Table 1. $\mathrm{pH}$ Characteristics as a Function of Admixture Agent

\begin{tabular}{cccccccc}
\hline Mixed amount (wt\%) & DBA & OR & Acetic acid & Formic acid & $\mathrm{H}_{2} \mathrm{SO}_{4}$ & $\mathrm{MgO}$ & $\mathrm{MgSO}_{4}$ \\
\hline 0 & & & & 7.64 & & & \\
1 & 6.17 & 7.18 & 6.96 & 6.90 & 6.24 & 7.66 & 7.63 \\
3 & 5.49 & 7.03 & 6.54 & 6.48 & 5.42 & 7.68 & 7.67 \\
5 & 5.34 & 6.35 & 6.10 & 6.01 & 5.28 & 7.71 & 7.70 \\
\hline
\end{tabular}




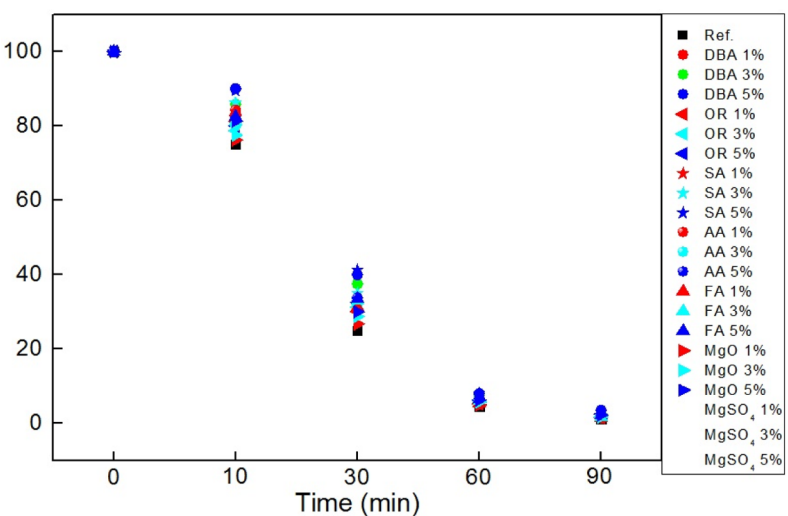

Fig. 2. Changes in $\mathrm{SO}_{2}$ concentration as a function of admixture $\left({ }^{*} \mathrm{SA}\right.$ : Sulfuric Acid, AA : Acetic Acid, FA : Formic Acid).

After completing the measurement of $\mathrm{SO}_{2}$ gas concentrations, and taking the samples showing a satisfactory desulfurizing efficiency for respective drying in a dryer at $40^{\circ} \mathrm{C}$ for $12 \mathrm{~h}$, XRD patterns were measured, and an example for the analysis results is shown in Fig. 3 and Table 2.

Considering the analysis results for XRD patterns as a function of admixture types, production of gypsum crystals was affirmed to be satisfactory in the samples with addition of $3 \%$ of DBA, $3 \%$ of OR and $1 \%$ of sulfuric acid. This suggests that the admixtures have sufficiently performed the buffering role for controlling $\mathrm{pH}$ of the desulfurizing agent in the solution. In addition, when G/C ratios shown in Table 2 were compared, the $\mathrm{G} / \mathrm{C}$ ratio was affirmed to appear
Table 2. Main Peak Intensity as a Function of Admixture

(unit : cps)

\begin{tabular}{cccc}
\hline & Calcite & Gypsum & G/C ratio \\
\hline DBA 3\% & 3424 & 1083 & 0.32 \\
OR 3\% & 3282 & 1099 & 0.33 \\
Sulfuric acid 1\% & 3137 & 1099 & 0.35 \\
\hline
\end{tabular}

slightly higher when OR and sulfuric acid were added compared with DBA which was universally employed in the conventional thermal power plants. Based on this, the $\mathrm{pH}$ buffering performance of OR can be seen to be higher than the equivalent as compared with that of DBA. Particularly, in the case of sulfuric acid, production of gypsum is considered to have been facilitated upon desulfurizing reaction as $\mathrm{SO}_{3}$ ions in the sulfuric acid solution performed not only a pH-buffering role but also a seed role enabling the production of gypsum. However, since OR is a solution prepared by fermentation of food wastes, there exist odors, while use for the process is considered possible in the case of sulfuric acid after the problems of having to pay attention in use, etc. have been solved.

Lastly, after taking the samples with addition of $1 \%$ of sulfuric acid for which the XRD pattern analysis had been completed, observation and EDS qualitative analysis of microstructures were conducted for limestone sludge by using a scanning electron microscope to analyze shapes and chemical compositions of the produced gypsum, with the results shown in Fig. 4.

Particle sizes of desulfurized gypsum are reported to be

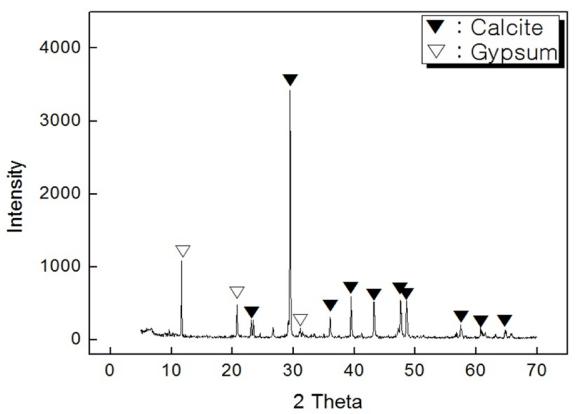

(a) Mixed with $3 \%$ of DBA

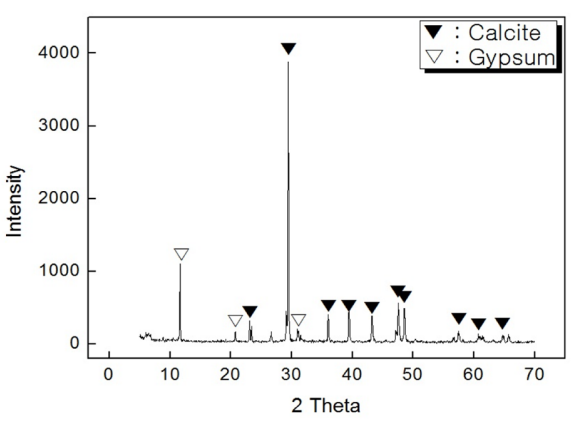

(b) Mixed with $3 \%$ of OR

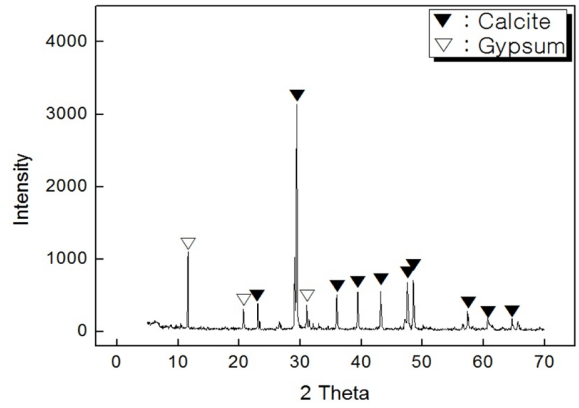

(c) Mixed with $1 \%$ of sulfuric acid

Fig. 3. XRD patterns of admixture. 

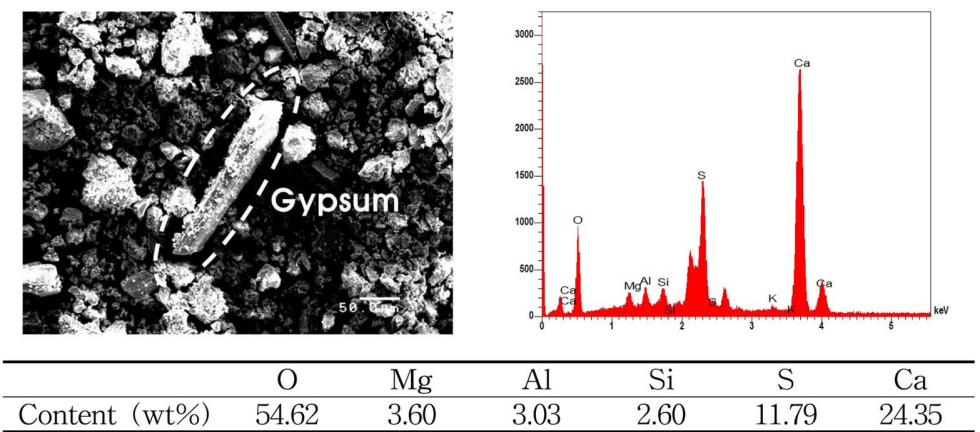

Fig. 4. Microstructure (200x) and EDS analysis of desulfurizing agent with $1 \%$ of $\mathrm{H}_{2} \mathrm{SO}_{4}$.

affected by the amount of inlet concentration of oxygen, and the crystal shapes affected by the $\mathrm{pH}$ and the stirring rate. Also, the crystal shapes show much variation depending on the several impurities contained in the limestone, and the gypsum shapes are known to be transformed from a plate shape to a needle shape as the quality of limestone is degraded. ${ }^{7)}$ Considering the picture for observation of a microstructure in Fig. 4, the shape of the produced gypsum is shown to be near a needle shape, although $\mathrm{CaCO}_{3}$ content of the limestone sludge used in the experiment was on the level of about $92 \%$, corresponding to a high-quality limestone. This production of the needle-shaped gypsum is considered attributable to the several impurities contained in the limestone sludge.

\section{Conclusions}

By using as the desulfurizng agent the samples of mixture of the limestone slurry used by thermal power plants and the limestone sludge produced in iron-making processes, experiments for comparison of desulfurizing performance were conducted as a function of types and contents of the admixture.

According to the experimental results for removal of $\mathrm{SO}_{2}$ gas, noteworthy results were observed in the increase of desulfurizing efficiencies due to DBA, OR(acidic solution prepared by fermentation of food wastes) and sulfuric acid, although the changes in desulfurizing efficiencies resulting from alkali admixtures were shown to be slight. According to the results of considering Gypsum/Calcite ratios through analysis of desulfurizing efficiencies and XRD patterns, in particular, it could be seen that the most satisfactory desilfurization efficiency was exhibited when OR and sulfuric acid were added. However, there exist odors in the case of OR since it is a solution prepared by fermentation of food wastes, while use in the process is considered possible in the case of sulfuric acid after the problems of having to pay attention in use, etc. have been solved.

Also, according to the observation results for microstructures of the produced desulfurized gypsum by using a scanning electron microscope, needle-shaped desulfurized gypsum was observed. This suggests that low-quality desulfurized gypsum was produced due to the effects of the impurities contained in limestone sludge even if desulfuring reaction was implemented by using high-quality limestone. Thus, it is considered that the measures to improve a purity of the produced desulfurized gypsum should be reviewed through continuous research and development in the future.

Based on the above experimental results, it is considered that economic and eco-friendly effects may be derived as a result of wastes recycling, etc. if the limestone used in the past can be substituted by application to the Flue Gas Desulfurizaton process of the limestone sludge as a byproduct of iron-making processes.

\section{REFERENCES}

1. J. B. Frandsen, S. Kiil, and J. E. Johnsson, "Optimization of a Wet FGD Pilot Plant Using Fine Limestone and Organic Acids," Chem. Eng. Sci., 56 [10] 3275-87 (2001).

2. S. K. Seo, Y. S. Chu, K. B. Shim, J. K. Lee, H. Song, and Y. M. Yun, "A Study on the Application with Limestone Sludge at Flue Gas Desulfurizing Process," J. Korean Ceram. Soc., 51 [6] 1-9 (2014).

3. N. Ukawa, T. Takashina, N. Shinoda, and T. Shimizu, "Effexts of Particle Size Distribution on Limestone Dissolution in Wet FGD Process Applications," Environment Prog., 12 [3] 238-42 (1993).

4. P. K. Chan and G. T. Rochelle, "Limestone Dissolution: Effects of $\mathrm{pH}, \mathrm{CO}_{2}$, and Buffers Models by Mass Transfer," ACS Symposium Ser., 188 75-9 (1982).

5. E. H. Kim, J. C. Lee, H. K. Lee, and I. W. Kim, "Effect of Mixed Organic Acid admixtures on $\mathrm{SO}_{2}$ Absorption in Wet Flue Gas Desulfurizing Process," Hwahak Konghak, 36 [5] 827-31 (1998).

6. J. C. S. Chang and J. D. Mobley, "Testing and Commercialization of Byproduct Dibasic Acid as Buffer Admixtures for Limestone Flue Gas Desulfurizing Systems," J. Air Pollut. Control Assoc., 33 [10] 955-62 (1983).

7. P. Tesarek, J. Krchalova, J. Kolisko, P. Rovnanikova, and R. Cerny, "Flue Gas Desulfurizing Gypsum: Study of Basic Mechanical, Hydric and Thermal Properties," Construction and Building Materials, 21 1500-9 (2007). 